\title{
Development of a Learning Environment to Enhance Preservice Physics Teachers' Diagnostic Competence in Terms of Students' Conceptions
}

\author{
Ingrid Krumphals ${ }^{1 *}$, Claudia Haagen-Schützenhöfer ${ }^{1}$ \\ ${ }^{1}$ Department of Physics Education Research, University of Graz, AUSTRIA
}

Received 14 September 2020 - Accepted 26 December 2020

\begin{abstract}
Teachers' diagnostic competence is fundamental for supporting students' individual learning processes and must be fostered in teacher education. Following a design-based research approach, a learning environment is developed focusing on preservice physics teachers' diagnostic competence in diagnosing students' conceptions. A core element of the learning environment are video vignettes of high school students solving tasks on mechanics. The learning arrangement was implemented in a bachelor's level physics didactics course. We aimed to identify supportive and obstructive elements for the preservice teachers' learning processes when training with the video vignettes to inform the redesign of the learning environment. The working phases centred around the training video vignettes were videotaped and data of four groups of preservice teachers was analysed with thick description. We reconstructed preservice teachers' intentions of action to gather a deeper understanding of supportive and obstructive elements. Among other findings, results show that preservice teachers' gaps in content knowledge highly influence the training situation.
\end{abstract}

Keywords: design-based research, diagnostic competence, diagnostic process, teacher education, video vignettes

\section{INTRODUCTION}

Diagnostic competence is seen as a key component of teachers' professional competence (Weinert, 2001). Teachers' diagnostic skills effect teachers' instructions (e.g., lesson planning and teaching, dealing with heterogeneity). Consequently, they are the basis for adaptive teaching and for fostering students' individual learning processes (see e.g., Vogt \& Rogalla, 2009).

In an educational context diagnosis is a very broad concept and is seen to comprise numerous actions of a teacher carrying out a diagnostic process which leads to a diagnostic judgement - the final diagnosis. While aiming at a (final) diagnosis, different diagnostic objectives are covered (learning behaviour, language, content knowledge, etc.). Accordingly, the diagnostic process varies in methods and time frames (more detailed description can be found in e.g., von Aufschnaiter et al., 2015). Nevertheless, diagnosis aims at determining students' conceptual status in order to choose appropriate interventions that promote students' individual conceptual development (Ingenkamp \&
Lissmann, 2008). In brief, diagnostic skills are the key to effectively adapt teaching.

In Austria, PISA results show that science teaching in school seems to be less adaptive than in other OECD countries (Suchań \& Breit, 2016). Therefore, especially for Austria, the importance of enhancing and training teachers' diagnostic competence is particularly important and must be part of teacher education.

Several approaches to enhance preservice teachers' diagnostic competence have already been undertaken in the field of science subjects (see e.g., Steffentorweihen \& Theyßen, 2018; Tolsdorf \& Markic, 2018). However, these studies do not identify how preservice teachers' learning processes are shaped concerning diagnosis and which factors influence diagnosis itself. One way of looking at relevant factors for diagnosis in school to enhance students learning is to consider components of planning instruction and quality factors identified for good instruction (see e.g., Hattie, 2012; Helmke, 2009) for example cognitive activation, student centred instruction, individual learning support. In order to

(c) 2021 by the authors; licensee Modestum. This article is an open access article distributed under the terms and conditions of the Creative Commons Attribution License (http://creativecommons.org/licenses/by/4.0/).

\ingrid.krumphals@uni-graz.at (*Correspondence) $\$ claudia.haagen@uni-graz.at 


\section{Contribution to the literature}

- Fostering teachers' diagnostic skills must start with teacher education. In this paper the development of a learning environment to foster preservice physics teachers' diagnostic competence to diagnose students' conceptions is reported by using a design-based research approach.

- Diagnosis and especially the diagnostic process carried out by teachers is still not clearly understood. We describe a diagnostic process model focused on diagnosis of students' conceptions which helps to understand the ideal diagnostic process concerning students' conceptions.

- The results derived by the means of thick description show deeper insights in preservice physics teachers' difficulties when acquiring diagnostic skills related to students' conceptions with video vignettes.

adapt instruction to students' perspectives (Weinert et al., 1989), one essential part in physics education is teachers' considering students' conceptions to create a supportive learning environment (Duit, 1994).

In conclusion, there is insufficient knowledge in science education research on (preservice) teachers' learning processes concerning diagnosis but there is a great need for the enhancement of preservice teachers' diagnostic skills in teacher education. Hence, we are designing a learning environment using a design-based research (DBR) approach (Barab \& Squire, 2004; HaagenSchützenhöfer \& Hopf, 2020) to inform domain-specific theory and practice in higher education. In our study we implemented a learning environment in a physics didactics course and aimed to gather deeper knowledge on preservice teachers' learning behaviour regarding their diagnostic competences in diagnosing students' conceptions ${ }^{1}$.

In this article we present the design of the first version of the learning environment and results of the analysis of the first implementation. Furthermore, we focused on identifying supportive and obstructive elements for preservice teachers' learning processes when working with video vignettes which are a core element of the learning environment. The results of the first intervention were used to improve the design of the learning environment for the next implementation cycle.

\section{THEORETICAL BACKGROUND}

In this section we discuss the topic of diagnostic competence and describe an adapted model of the diagnostic process for teaching contexts. Then the perspective of expert-novice research and recent research on preservice teachers' diagnostic competence serve as a basis for the design principles of the presented first version of learning environment.

\section{Diagnostic Competence}

Diagnosis in an educational context includes all diagnostic activities that evaluate learners' conditions and skills to help to understand learners' actions to foster (individual) learning processes (Ingenkamp \& Lissmann, 2008). Teachers' diagnostic competences influence students' learning through many teachers' actions related to aspects of quality of instruction (e.g. taking students perspectives into account (Duit et al., 2012), applying feedback (Black \& Wiliam, 2003) or adaptive teaching (Beck et al., 2008)). However, the mechanism for how teachers' diagnostic competence influences students' learning outcomes is still unclear.

In research there is no consensus on the construct of diagnostic competence. This results partly from not differentiating systematically between (1) the aim of diagnosis concerning adaptive teaching or selection and (2) the methods used to collect information for diagnosis (von Aufschnaiter et al., 2015). In this article we focus on diagnosis, which aims to serve as a basis for adaptive teaching (Fischer et al., 2014) and helps to optimize students' learning processes and, thus, is a precondition for high quality instruction (Praetorius et al. 2012). All in all, we see diagnostic competence as a bundle of teachers' knowledge, skills, motivation and beliefs which influence the quality of the diagnostic judgment - hereafter called diagnosis and/or the diagnostic processes (see e.g., Herppich et al., 2017; von Aufschnaiter et al., 2015; Weinert, 2001). In our project, diagnostic competence is seen as a continuum of dispositions, processes and performance (Blömeke et al., 2015) and is mainly related to teaching practice (Leuders et al., 2018).

\section{Diagnostic Process}

A diagnosis is always based on a diagnostic process following a diagnostic objective. In teaching contexts, objectives of diagnosis are very diverse (affective, cognitive, linguistic, etc.). Consequently, teachers need to apply different diagnostic activities resonating with these objectives. In our project we focus on one diagnostic objective - the diagnosis of students' conceptions $^{2}$ - since, when designing learning

\footnotetext{
${ }^{1}$ In this article with the term "students' conceptions", we mean students' ideas on physics content which influence their individual learning processes.

2 In the context of our research, the term students' conceptions comprises students' ideas of a scientific topic of physics which must be considered in further instruction to optimize students' learning processes in physics.
} 


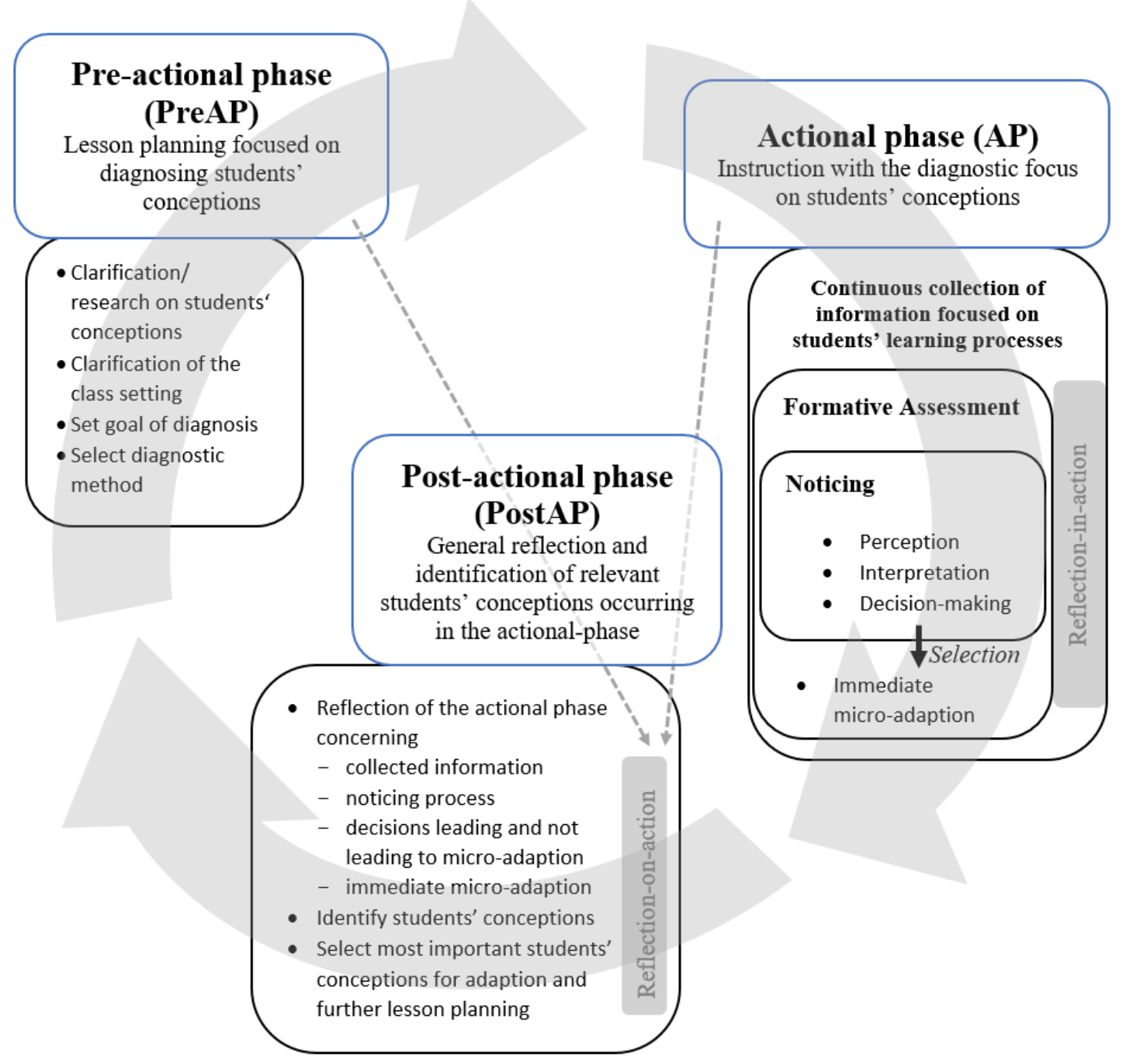

Figure 1. Diagnostic process to diagnose students' conceptions

arrangements, considering students' conceptions is fundamental for high quality instruction (e.g., Duit et al., 2012).

The theoretical basis for the design of our learning environment is the process model of teachers' diagnostic competence concerning students' learning behaviour by Klug et al. (Klug et al., 2013; Klug, Bruder, \& Schmitz, 2016; Klug, Gerich, \& Schmitz, 2016), which we adapted to our goals. The adapted model describes an idealized diagnostic process ${ }^{3}$ that focuses on the diagnosis of students' conceptions in conventional school settings. This idealized diagnostic process consists of three main phases related to planning, teaching and reflecting on the teaching and learning process (see Figure 1): (1) the pre-actional phase (PreAP), where lesson planning takes place; (2) the actional phase (AP), where teaching and data collection for diagnosis happens and (3) the postactional phase (PostAP) after instruction, where teachers analyse the data more deeply, aiming to identify relevant students' conceptions for planning further instruction.
Additionally, in the PostAP teachers consciously reflect on their actions during the two previous phases to improve professionally.

In general, in this idealized model, teachers enter the cycle in the PreAP for example when they start a new topic (in general the cycle can refer to one lesson or a sequence of lessons on a topic). Then they pass through the cycle several times. The iterative process ends ideally with the PostAP for example when a specific topic is finished and a new topic must be planned. PreAP, AP and PostAP are not necessarily chronologically and strictly separated from each other. They are, rather, intertwined and can take place in a lesson or a thematic sequence. Thus, the PostAP and PreAP especially cannot be seen as temporally separate, taking place at different moments in time. It is very likely that at least some reflective processes - rooted in observations of the instructional phase - are carried out at the same time as ideas about planning the next lesson (these ideas can also appear in the AP but teachers consciously take time to

${ }^{3}$ In our study, with "diagnostic process", we mean the procedure teachers carry out to accomplish a final diagnosis, which then is the basis for adaptive teaching and the next cycle of the diagnostic process. 
reflect on them in the PostAP). In contrast, the AP is clearly related to lessons, where in-action-reflection and immediate micro-adaption of instruction take place. Thus, the AP differs from the PostAP mainly in terms of immediate micro-adaptions and in-action-reflection during instruction when compared to macro-adaption and deeper reflection-on-action.

In the next paragraphs we describe the three phases and outline how we conceptualize them regarding the diagnosis of students' conceptions in more detail:

The diagnostic process starts with the pre-actional phase (PreAP), where teachers consciously plan their instruction. Following the model of educational reconstruction (Duit et al., 2012), this planning process should contain several components: Clarification and analysis of science content, investigation of students' perspectives and design and evaluation of teaching and learning environments. Additionally, the teacher sets diagnostic goals and selects the appropriate diagnostic methods. In our case, the diagnostic dimension of the planning process focuses on the diagnosis of students' conceptions.

The next phase of the diagnostic process is the actional phase (AP). It takes place during instruction. While teaching, teachers collect information framed by previously set (PreAP) diagnostic goals. Therefore, formative assessment (Black \& Wiliam, 1998; McManus, 2008) as a diagnostic focus plays an important role in discovering gaps between what has been taught and has been learned in the classroom. During the AP, teachers are continuously collecting information on students' behaviour - in our case students' conceptions are addressed. In this phase, teachers' noticing (Sherin \& van Es, 2009) and knowledge-based reasoning are important factors in informing instruction and consequently in supporting students' learning progresses (van Es \& Sherin, 2008). More specifically, teachers undergo a noticing process (see detailed description for example in Sherin et al., 2011; van Es \& Sherin, 2002), which means they perceive critical incidences of the classroom situation, interpret them and make decisions for further instructional steps (perception, interpretation and decision making - PID model see Santagata \& Yeh, 2016). At that point, teachers decide either to immediately micro-adapt their teaching or not. A microadaption always aims to meet students' learning needs better and results in actions such as explaining the content once more and/or in more depth, adding additional content/activities/representations to consolidate students' thinking, initializing a cognitive conflict. Certainly, to inform micro-adaptions the processes of noticing and formative assessment can occur repeatedly during the AP. Additionally, in-actionreflection (Greenwood, 1993; Schön, 1987) - where teachers think about their teaching on a meta level while teaching - continuously occurs in this phase.

In the third phase - the post-actional phase (PostAP) - teachers reflect on several levels. These multiple reflective processes are supposed to inform further lesson planning and instruction. Therefore, teachers systematically interpret information about students collected during the AP (observations, worksheets, etc.). Further, teachers reflect on their actions in the classroom including the formative assessment processes, their micro-adaption(s), their noticing processes, and their final teaching decisions. Here, teachers recall, reflect and interpret the episodes of the AP in which they set a reminder for later consideration outside the classroom situation, such as to reflecting on the need to address certain aspects in the next lesson or to analyse certain incidents in more detail. The process of post-actional reflection (reflection-on-action in contrast to in-actionreflection in the AP) is essential in the third phase. The interpretations and insights gathered in the reflection process result in macro-adaptions (e.g., of the sequence planning or individual acquired teaching-scripts of teachers). In our case it cannot be assumed that macroadaptions are based on teaching-scripts since at this stage preservice teachers have limited teaching experience and, therefore, not many teaching-scripts available.

Regarding our focus on students' conceptions, in the PostAP collected information on students' behaviour is analysed and interpreted and may uncover additional students' conceptions that were either not recognized or at least not addressed during the AP. Based on this reflective output, teachers select main students' conceptions and/or issues for further macro-adaption (in the AP this may lead to micro-adaption).

To sum up, the aim of the PostAP is the identification of the most important aspects that need to be considered for further instruction - a macro-adaption - applying instructional strategies (e.g., by following a conceptual change approach (Duit et al., 2013)) to support students' learning processes.

After the third phase, the diagnostic process starts from the beginning with the PreAP. The conclusions made in the PostAP form the basis for the PreAP of the next lesson and so on.

\section{Diagnostic Competence in Expert-Novice Research}

To carry out the above-mentioned diagnostic process with the focus on students' conceptions, teachers must be able to diagnose relevant students' conceptions. How teachers acquire the needed diagnostic competence best is still unknown. Here, findings of expert-novice ${ }^{4}$ research can help to gain more insight into teachers'

${ }^{4}$ In this article, we understand the term "experts" as experienced teachers, while "novices" are preservice teachers, teaching interns or teachers in their first years. 
diagnostic competence. The analyses of actions and students' cognitive processes of experienced teachers (experts) and unexperienced teachers (novices) while diagnosing helps to more deeply understand how effective diagnostic processes function and therefore how diagnostic competence may be supported (van Ophuysen, 2010).

Several research findings indicate that novice teachers struggle to focus on students' learning processes during class. Levin et al. (2009) found in their study with novice teachers that they mainly focus on their actions and internal processes while students' learning processes are not or are barely consciously perceived. As one main reason for novices' lack of perception of students' learning processes, Levin et al. (2009) identified, that novices are mainly encouraged in their internships to acquire classroom management skills and to cover the content of the curriculum from an input perspective. This high cognitive workload reduces their capacity to additionally focus on students' thinking, especially since classroom interactions are very complex and often overwhelming for novices (Levin et al, 2009). Consequently, preservice teachers must learn to focus on students' learning processes to perform ideal diagnostic processes and meet the diagnostic aims.

Star and Strickland (2008) investigated the impact of watching videotaped lessons on preservice teachers' noticing ability. They found that preservice teachers mainly focus on the teacher and that they remember aspects of classroom management best (Star and Strickland, 2008). In contrast, issues concerning subject specific learning and instructional quality are barely recognized, the focus is clearly not put on teaching and learning processes and stays on clearly visible incidents on the surface level. Furthermore, preservice teachers are barely able to distinguish between relevant and nonrelevant classroom incidents that signpost the need for an adaption in order to support students' learning processes adequately (Berliner, 2001). Preservice teachers especially struggle to elementarise content to their students' learning needs which is crucial in diagnosing students' conceptions.

In contrast to novice teachers, expert teachers interpret classroom incidences in more depth and more precisely (van Es \& Sherin, 2002). They (systematically) try to identify learning problems drawn from their experience to understand and explain difficult classroom situations (van Es \& Sherin, 2002). Thereby, their interpretations of lesson observations frequently rely on evidence-based information (van Es \& Sherin, 2002). In contrast, novices tend to merely describe students' mistakes on a surface level without connecting them to deeper learning processes which results in criticizing and assessing students' actions without giving any suggestions to address uncovered problems (Carter et al., 1988; Sabers et al., 1991).
Overall, we can draw some conclusions concerning diagnostic processes form expert-novice research but still a great deal of research must be performed to (empirically) grasp and understand the diagnostic process and diagnostic competence of teachers. Nevertheless, research literature identifies several factors that hinder novices in carrying out ideal diagnostic processes, and these factors must be considered when designing a learning environment concerning diagnosis.

\section{Diagnostic Competence in Teacher Education}

The need to improve teachers' diagnostic competence in teacher education has resulted in several instructional approaches: Training of diagnostic skills through guided experience in learning labs (e.g., Meister et al., 2020; Steffentorweihen \& Theyßen, 2018), through didactics courses connected to internships in school (e.g., Tolsdorf \& Markic, 2017) and through video-based training (e.g., Alonzo \& von Aufschnaiter, 2018; Star \& Strickland, 2008; Tekkumru-Kisa et al., 2018).

Video vignettes are an especially promising vehicle for promoting competences in terms of noticing and/or diagnostic competences (Blomberg et al., 2013; Blomberg et al., 2014; Seidel et al., 2013; Tekkumru-Kisa et al., 2018). In particular, Meister et al. (2020) found hints that the development of process diagnostic skills (analysis of the learning processes of students) of preservice teachers can be supported by using video vignettes as training situations in teacher education courses. Additionally, video vignettes seem to help preservice teachers to better focus on the diagnostic process (Meister et al., 2020; Steffentorweihen \& Theyßen, 2018).

Nevertheless, preservice teachers face obstacles when working with video vignettes in terms of interpreting students' thinking (von Aufschnaiter \& Alonzo, 2018). They can notice students' utterances which are relevant to understand students' conceptions, but they struggle to interpret these utterances in order to adapt further instruction to individual needs (von Aufschnaiter \& Alonzo, 2018). It is unclear, why preservice teachers struggle with these interpretations and insufficient knowledge exists on how preservice teachers' learning processes need to be shaped to acquire diagnostic competence. Deeper insights are needed to better understand preservice teachers' learning behaviour when acquiring diagnostic competence to develop the most supportive learning environments.

Although videos seem to support the development of diagnostic skills, their use in preservice teacher education must be well thought out, as research also shows several negative effects. In general, videos need to be embedded in learning environments that match the learning objective (Blomberg et al., 2013). Especially when integrating a video imitating a real-world task in a 
learning environment, the issue of cognitive overload needs to be considered (van Merrienboer et al., 2003).

\section{DESIGN OF THE FIRST VERSION OF THE LEARNING ENVIRONMENT}

Addressing the goal of fostering preservice teachers' diagnostic competence of identifying students' conceptions, we aimed to develop a learning environment for physics teacher education. We employ a design-based research (DBR) approach (Barab \& Squire, 2004) since this paradigm focuses theory-intopractice aspects while carrying out systematic iterative redesign cycles and interventions. This leads to the design of authentic learning environments and informs theory on domain-specific learning processes.

\section{Design Principles}

Following a DBR approach, first design principles (DPs) are deduced from theory and research findings. These DPs guide the design process of the first version of the learning environment. Based on the data collected during the implementation of the learning environment in authentic settings, the DPs are refined, and the learning environment is redesigned in iterative cycles.

In our case these DPs are:

DP1. Learning processes of preservice teachers are seen in a constructivist way (Duit, 1996).

DP2. In teaching situations, preservice teachers must learn to focus on students' learning processes and shift away from a teacher-centred perspective (Levin et al., 2009).

DP3. Simplified representations of teaching and learning must be used to reduce the level of difficulty so as to prevent cognitive overload (Grossman et al., 2009).

DP4. Authentic representations of school settings must be used to help preservice teachers translate their behaviour into real situations (Schubert et al., 2001).

DP5. Preservice teachers must receive a "well-dosed practice in order to understand the complexity of classrooms and be able to integrate their knowledge about teaching." (Blomberg et al., 2013, p. 106)

DP6. Diagnostic processes of students' conceptions are complex and can only be acquired in several steps following similar schemata of action. These schemata must be trained again and again. Preservice teachers acquire easy accessible schemata which they can easily integrate in future real teaching situations
(Livingston \& Borko, 1989, p. 39). Preservice teachers learn to follow the model of diagnostic process outlined above (see section Diagnostic Process):

- Preservice teachers must know general students' conceptions concerning the topic of mechanics. (PreAP)

- Preservice teachers must have the opportunity to undergo a noticing process (PID model - Santagata \& Yeh, 2016). (AP)

- Based on observations from the AP, preservice teachers must learn to draw their interpretations from evidence only and reflect on their actions and the collected information. (PostAP)

- Based on their interpretations, preservice teachers must learn to adapt further instruction (Vogt \& Rogalla, 2009). (PreAP)

\section{Implementation of the Learning Environment}

The first version of the learning environment is based on the above-mentioned DPs and is implemented in a physics didactics course (2 ECTS credits $\left.{ }^{5}\right)$ for a maximum of 20 preservice physics teachers in their bachelor studies ( $6^{\text {th }}$ semester). The course comprises 10 presence units (each 120 minutes) and takes place parallel to an internship ${ }^{6}$ in secondary level schools, focusing on diagnosis and assessment (given by the curriculum). It accompanies the preservice teachers' observing physics lessons and teaching physics aiming to support preservice teachers in enhancing their skills concerning lesson planning, developing and performing assessments, teaching and reflection with the focus on diagnosis and assessment. The designed learning environment is implemented in four units of this course. It aims to support the development of preservice teachers' diagnostic skills concerning the diagnosis of students' conceptions (DP2). In this article we will focus on one main part of the physics didactics course namely the implementation of the learning environment (covering DP1-6). Meeting DP6 - implementing easily accessible schemata of action for preservice teachers the intervention in the physics didactics course follows the diagnostic process model, and therefore these phases are passed through when working with the three training video vignettes (video vignette 1, 2 and 3 (V1, $\mathrm{V} 2$ and $\mathrm{V3})$ ).

\section{Intervention}

The intervention starts with theoretical input on the topic of diagnosis. Types of diagnosis, the importance of

${ }^{5}$ ECTS stands for "European Credit Transfer System"

6 The internship comprises 3 ECTS credits including 5-10h of classroom observation and about 8-10h of individual teaching. During the internship, preservice teachers are accompanied and supported by a teacher (mentor) at the school of their internship. 


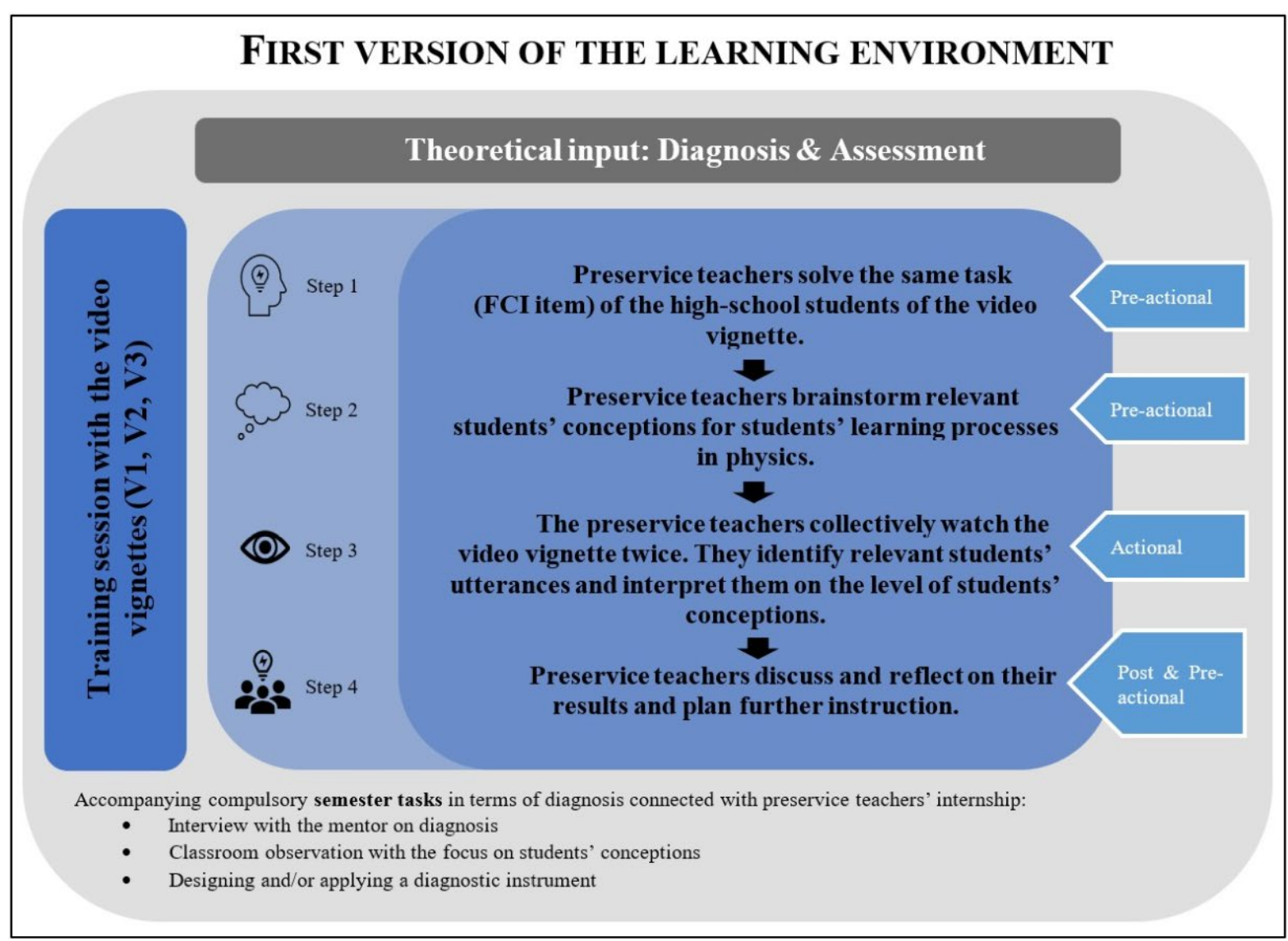

Figure 2. The structure of activities centred around a training session working with a video vignette in the first version of the learning environment

diagnosis in a teaching and learning context, the diagnostic process, diagnostic aims and diagnostic methods are discussed. Then, three authentic video vignettes (V1-V3, each 3-5 minutes) (Rath, 2017) are embedded in the learning environment as learning opportunity which the preservice teachers watch together in a plenary setting (DP4). Each video vignette shall represent a snapshot of students in groups working on a diagnostic task in mechanics, which focuses on a certain basic concept of mechanics (Newton's laws). A group of three to four high school students is working on one of these basic concepts, and their task is to solve a corresponding FCI item (Hestenes et al., 1992). On the level of the preservice teachers' seminar, the choice for mechanics was mainly based on the fact that by the $6^{\text {th }}$ semester, they have already attended all formal learning opportunities for mechanics in their studies. In brief, while working with the video vignettes, preservice teachers must focus on students' learning processes (DP2), and they face simplified representations, since the short period in the video vignettes shows only a small group of students instead of observing an entire class (DP3). Additionally, DP4 and DP5 are covered since we used authentic representations to provide "well-dosed" practice for preservice teachers.

To minimize cognitive load (van Merrienboer et al., 2003) and reduce the level of difficulty of the tasks (Grossman et al., 2009), we additionally used a scaffolding approach (DP3). To be more specific, the preservice teachers are supported in dealing with the training video vignettes by additional elements and group-discussion phases. The intensity of scaffolding is gradually minimized from training session (TS) to TS.

The integration of every training video vignette into the seminar follows the phases of the diagnostic process model (DP6) and each TS with one video vignette takes about 60 minutes. The preservice teachers are instructed (in group- and/or individual-work phases) to diagnose relevant students' conceptions emerging in these video vignettes. Additionally, they are guided by worksheets. The worksheets contain three parts: the respective FCI item, possible relevant students' conceptions (for high school students dealing with the FCI item) and space for preservice teachers' notes on observations and interpretations performed when watching the video vignette (students' utterances and students' conceptions). As Figure 2 shows, each TS that is centred around a video vignette, has a similar structure and consists of four steps.

In step 1, the preservice physics teachers must solve the same task as the high school students in the video vignette (PreAP). Due to the scaffolding approach mentioned above, the preservice teachers get the opportunity to consolidate and discuss their solutions in small groups in the TS when working on V1 (TS-V1) and V2 (TS-V2). At a later stage, in the TS with V3 (TS-V3), 
they solve the task completely on their own and are not allowed to discuss their ideas with peers. In general, step 1 is designed to simulate the clarification of content as described in section Diagnostic Process as part of the PreAP.

In step 2, the preservice teachers must brainstorm students' conceptions that may occur when high school students work on a task as given in the related vignette. Again, due to scaffolding considerations, the preservice teachers are supported in TS-V1 by a list of several students' conceptions taken from the literature and adapted to the FCI item with the option to extend this list. Thus, in TS-V1 the preservice teachers recapitulate their knowledge on students' conceptions in mechanics. Then, in TS-V2 and TS-V3 they must brainstorm the students' conceptions by themselves. To sum up, step 2 should prompt preservice teachers to activate their knowledge on students' conceptions and encourage them to think from the students' point of view.

In step 3, the preservice teachers watch the video vignette twice and are instructed to identify crucial students' utterances which point to underlying students' conceptions. On the worksheet students' utterances and conceptions are separated by two columns which must be filled in. In this step no scaffolding elements are used, and the procedure is identical in all TSs (TS-V1, TS-V2 and TS-V3). In brief, in step 3 preservice teachers are stimulated to carry out a noticing process by focusing on the first two steps of the PID model (Santagata \& Yeh, 2016) - perceiving and interpreting.

In step 4, preservice teachers reflect on the relevance of the students' conceptions identified in the video vignette and in peer groups they negotiate the relevance in order to address them in the next lesson (based on the overall learning goals set for mechanics). The transition from step 3 to step 4 is blurred since thoughts and considerations about students' conceptions also occur in step 3. Step 4 is related to the PostAP and the PreAP of the next iteration of the model of diagnostic process, and thus is framed by lesson planning and considerations for the next lesson. In all TSs, preservice teachers compare and discuss their results regarding content clarification and students' conceptions identified in the video vignette framed by their goals for further instruction. Thus, preservice teachers should practice transferring their findings to improve and plan further instruction (PostAP).

Following a scaffolding approach, the supportive elements for the phase of lesson planning are gradually minimized. In TS-V1, preservice teachers get two drafts of authentic lesson plans ${ }^{7}$ for the next lesson after the episode observed in the vignette. They must analyse the two lesson plans regarding the quality of the alignment of the instruction with the found students' conceptions. Additionally, they discuss and give suggestions for the lesson plans considering previously identified students' conceptions. In TS-V2 the preservice teachers get a list of misconceptions mixed in with basic content ideas in mechanics. First, they must clarify on their own if it is a student's conception which is incorrect regarding physics content (misconception), and therefore important to consider for further learning processes, or if it is indeed a correct idea in mechanics. Then they discuss their results with their peers. Preservice teachers again consolidate their knowledge in mechanics and on students' conceptions. Afterwards they decide on most relevant students' conceptions for further instruction, which serves the mutually agreed objective of the next lesson and the basis for their further lesson planning. In TS-V3, the preservice teachers plan the following lesson in peer groups without any supportive material. In brief, in step 4 of V1-V3 preservice teachers gradually learn to plan further instruction based on identified students' conceptions in the video vignettes and on basic learning goals in mechanics.

\section{RESEARCH QUESTION \& RESEARCH DESIGN}

Following a DBR approach, the learning environment is developed in iterative cycles. Research results of the first intervention are the basis for the second version of the learning environment. Thus, our research question focuses on better understanding the learning behaviour triggered by the design of the first version of our learning environment in our sample of preservice teachers. The main research question is: Which supportive and/or obstructive elements of a learning environment designed to foster skills in diagnosing students' conceptions can be identified that influence preservice teachers' learning behaviour during training sessions with video vignettes?

The peer group phases of the preservice teachers during the intervention with the training video vignettes (V1-V3) are videotaped to get deeper insight into their discussions and to obtain indications of their learning behaviour. We decided to analyse data of the working phases of four peer groups with different preservice teachers involved to get a broad impression of their learning behaviour (see Table 1). Therefore, we videotaped seven preservice teachers in different group constellations (the physics didactics course was attended by 14 preservice teachers). The videotapes were transcribed and served as the basis for the analysis. More details of the sample are shown in Table 2.

7 The provided drafts of lesson plans do not contain an exhaustive description of each instructional phase of the lesson. This serves as fruitful ground for discussions and suggestions for improvement of these lesson plans. 
Table 1. Details on analysed videotapes

\begin{tabular}{ccccc}
\hline Videotape & Video-vignette & $\begin{array}{c}\text { Phases of the diagnostic } \\
\text { process model }\end{array}$ & $\begin{array}{c}\text { Steps } \\
\text { Number of preservice teachers in } \\
\text { the peer-group (ID: SX) }\end{array}$ \\
\hline 1 & V1 & PreAP+AP & $1-3$ & $4(\mathrm{~S} 1, \mathrm{~S} 2, \mathrm{~S} 3, \mathrm{~S} 4)$ \\
2 & V1 & PostAP & 4 & $5(\mathrm{~S} 1, \mathrm{~S} 2, \mathrm{~S} 5, \mathrm{~S} 6, \mathrm{~S} 7)$ \\
3 & V2 & PreAP+AP & $1-3$ & $4(\mathrm{~S} 1, \mathrm{~S} 3, \mathrm{~S} 4, \mathrm{~S} 5)$ \\
4 & V2 & PostAP & 4 & $4(\mathrm{~S} 1, \mathrm{~S} 3, \mathrm{~S} 6, \mathrm{~S} 7)$ \\
& V3 & PreAP+AP+PostAP & $1-4$ & \\
\hline
\end{tabular}

Table 2. Details of the sample (gender and solved FCI items in a pre-post-survey)

\begin{tabular}{cccc}
\hline \multirow{2}{*}{ Preservice Teacher } & Gender & \multicolumn{2}{c}{ Correct solved FCI items* $^{*}$} \\
\cline { 3 - 4 } & & Pre & 5 \\
S1 & $\mathrm{f}$ & 4 & 4 \\
S2 & $\mathrm{f}$ & 2 & 5 \\
S4 & $\mathrm{m}$ & 4 & 6 \\
S5 & $\mathrm{f}$ & 6 & 3 \\
S6 & $\mathrm{f}$ & 2 & 4 \\
S7 & $\mathrm{m}$ & 4 & 5 \\
\hline
\end{tabular}

*At the beginning (pre) and at the end (post) of the training with the video vignettes the preservice teachers got 6 FCI items to check their content knowledge.

\section{Method of Analysis}

The videotapes were analysed by means of thick description (Geertz, 1973; Ponterotto, 2006). Thick description is an ethnographic method which aims to detect structures and/or patterns to obtain deeper insights on the subjects' actions (Geertz, 1973).

"... thick description is not simply a matter of amassing relevant detail. Rather, to thickly describe social action is actually to begin to interpret it by recording the circumstances, meanings, intentions, strategies, motivations, and so on that characterize a particular episode. It is this interpretive characteristic of description rather than detail per se that makes it thick" (Schwandt, 2007)

Thick description serves as the basis for thick interpretation (Denzin, 1989), which is making sense of individual behaviour from the thickly described sequences, and is followed by thick meaning. Therefore, this hermeneutic-ethnographic method allows for the reconstruction of an understanding of a complex topic (Freeman, 2014) and tries to reconstruct the variety of complex and interwoven internal and external structures present (Geertz, 2015). As the diagnostic process and especially the learning processes to acquire diagnostic competence are complex and still not understood, with thick description we aim to understand preservice teachers' actions and limitations in terms of acquiring diagnostic competence with the help of training video vignettes implemented in a physics didactics course. By the means of thick description, preservice teachers' intentions concerning their learning behaviour during the intervention with the training video vignettes can be reconstructed in detail and interpreted framed by the research question above and inform the next redesign.

The analysis followed four steps (see example in Table 3):

0 . The video-material was transcribed.

1. The situation was micro-sequenced and described in detail guided by the questions: Where? When? Who? What? How?

2. The detailed description was interpreted, and a reconstruction was carried out by outlining possible intentions of the individuals ${ }^{8}$ framed by the question: Why are individuals acting like this?

3. Last, thick meaning ${ }^{9}$ was densely extracted using the question: What does that mean for the individuals?

All these steps lead to a summary which contains only the essentials needed to understand behaviour (Leeds-Hurwitz, 2015) - in our case - preservice teachers' learning behaviour. The summary in the last step (step 3) forms the reconstructed results corresponding with the aim of capturing preservice teachers' intentions for their learning behaviour in depth when working with the training video vignettes. This

8 Clearly, not all possible intentions are gathered here, which is also not the aim. The interpretation phase corresponds with the research interest.

9 The interpretations of the previous step will be concisely summarised in considering essential parts necessary for the understanding of the individuals' behaviour regarding the research interest (Leeds-Hurwitz, 2015). This step covers the thickened conclusions and results derived from the data. 
Table 3. Excerpt (translated from German) - episode analysed with thick description

The excerpt shows the four steps of analysis based on an example of our video analysis where preservice teachers discuss observed students' conceptions after watching V3. S1 explains the students' conceptions she has identified. The high school students in the video vignette discussed forces on a ball rolling along a circular ball tube.

\begin{tabular}{|c|c|c|c|}
\hline Step 0 (transcript) & Step 1 (micro-sequencing) & Step 2 (interpretation and reconstruction) & $\begin{array}{l}\text { Step3 (extraction of thick } \\
\text { meaning) }\end{array}$ \\
\hline $\begin{array}{l}\text { [Timestamp 26:36] } \\
\text { S6: } \\
\text { "Maybe that the movement, } \\
\text { also the direction of } \\
\text { movement, so that the easy } \\
\text { way, the ball channel is there } \\
\text { and that there is no force } \\
\text { involved. And the momentum } \\
\text { will not work, and that the } \\
\text { momentum never occurs." } \\
\text { S7: } \\
\text { Briefly, typing on his } \\
\text { phone. } \\
\text { S1: } \\
\text { Listens to S6 and nods. } \\
\text { S2: } \\
\text { Listens to S6. } \\
\text { S6: } \\
\text { Looks to S2 who is } \\
\text { designated to take notes on } \\
\text { their group worksheet. } \\
\text { S2: } \\
\text { "Mhm. How should we } \\
\text { phrase that?" } \\
\text { S6: } \\
\text { "I don't know: Come up with } \\
\text { something." } \\
\text { S7: } \\
\text { Puts the smartphone away. } \\
\text { S1: } \\
\text { Looks at S2. } \\
\text { [Timestamp 26:54] }\end{array}$ & $\begin{array}{l}\text { S6 describes more than one } \\
\text { student's conception in a } \\
\text { very fragmented manner. } \\
\text { Her description is imprecise, } \\
\text { and as the introduction to } \\
\text { her explanation she uses the } \\
\text { word "maybe". First, on a } \\
\text { content level, S6 mentions } \\
\text { the direction of movement, } \\
\text { which may be given by the } \\
\text { ball channel, and second, she } \\
\text { mentions that momentum } \\
\text { does not occur. Her } \\
\text { explanation is } \\
\text { incomprehensible, and it is } \\
\text { unclear exactly what S6 } \\
\text { means. } \\
\text { S2 asks for help to rephrase } \\
\text { what S6 said, so that she (S2) } \\
\text { can write it down on the } \\
\text { worksheet of the group, but } \\
\text { S6 passes it back to her. The } \\
\text { other two preservice teachers } \\
\text { do not answer. } \\
\text { Meanwhile, S7 is briefly } \\
\text { distracted by his phone, and } \\
\text { S1 follows the discussion and } \\
\text { nods at the explanations of } \\
\text { S6. }\end{array}$ & $\begin{array}{l}\text { S6 describes her identified students' conceptions. } \\
\text { In her description she knows several problems } \\
\text { because she has little experience communicating } \\
\text { about students' utterances, which should be } \\
\text { interpreted in terms of students' conceptions. } \\
\text { S6 has troubles describing her thoughts and } \\
\text { conclusions. She is not able to take her thoughts } \\
\text { to the next level (adequate interpretation) and } \\
\text { communicate and rephrase her thoughts in a } \\
\text { comprehensible way. Therefore, her explanations } \\
\text { remain very fragmented, which also might stem } \\
\text { from her gaps in content knowledge (see previous } \\
\text { episodes). Additionally, it seems difficult for her } \\
\text { to put herself into the role of students to } \\
\text { understand their thoughts and so, she also } \\
\text { struggles to communicate on them. } \\
\text { This makes the communication in terms of } \\
\text { negotiation on students' conceptions very hard } \\
\text { for all preservice teachers in the peer group. } \\
\text { S2 struggles to follow S6 and she (S2) is unsure of } \\
\text { how to paraphrase the thoughts of S6 to write } \\
\text { them down on the worksheet, since she (S2) is the } \\
\text { designated writer. Thus, S2 asks the peer group } \\
\text { how they can rephrase the comment in a way that } \\
\text { she can write down. S6 thinks that S2 wants her } \\
\text { to rephrase her description, and, as S6 has huge } \\
\text { problems describing her thoughts, she feels } \\
\text { unable to do the rephrasing, so she simply passes } \\
\text { the task back to S2. } \\
\text { S7 is briefly distracted but keeps up and quickly } \\
\text { returns to listening to the discussion, because a } \\
\text { fundamental step (the interpretation of students' } \\
\text { utterances) must be completed working in the } \\
\text { peer group. } \\
\text { S1 listens to the conversation but does not help to } \\
\text { rephrase the explanations of S6, because she was } \\
\text { possibly only able to follow the explanations of } \\
\text { S6, but not to understand them in depth enough } \\
\text { to be able to rephrase the mentioned fragmented } \\
\text { thoughts/students' conceptions. }\end{array}$ & $\begin{array}{l}\text { The preservice teachers } \\
\text { (S6) show obstacles in } \\
\text { communication } \\
\text { concerning observed } \\
\text { high school students' } \\
\text { utterances and } \\
\text { interpreted students' } \\
\text { conceptions, because } \\
\text { they have little } \\
\text { experience with it. } \\
\text { Additionally, their (S6, } \\
\text { S1, S7, S2) gaps in } \\
\text { content knowledge (see } \\
\text { previous episodes) and } \\
\text { inability to put } \\
\text { themselves into the } \\
\text { learning process of a } \\
\text { high school student may } \\
\text { explain their imprecise } \\
\text { conversation. } \\
\text { Thus, for the preservice } \\
\text { teachers (S6) it seems } \\
\text { challenging to articulate } \\
\text { their thoughts regarding } \\
\text { interpretations and } \\
\text { communicate them at an } \\
\text { advanced (content) level. }\end{array}$ \\
\hline
\end{tabular}
There are no further attempts of phrasing the mentioned students' conception by S1. S4 starts another discussion ...

allows us to gather hints on obstacles and supportive elements in the learning process. Parts of the data were analysed in a team with a co-researcher to establish the communicative validity of the results.

\section{SELECTED RESULTS}

In this section, we will present the detected supportive and obstructive elements of the learning environment. Obstacles preservice teachers encounter in the TSs with the video vignettes include insufficient professional language proficiency with regard to physics and physics didactics, their gaps in knowledge regarding students' conceptions (in our case in mechanics), and therefore difficulties in phrasing and talking about students' conceptions. Due to limitations in length of the article, we focus on one obstacle that influences the entire learning process regarding diagnostic competence, namely preservice teachers' gaps in content knowledge. We start by presenting selected supportive elements and then focus on the effects of preservice teachers' gaps in content knowledge on their learning behaviour during the use of the video vignettes. Then, we distinguish between impacts of peer discussions, on identifying students' conceptions and on planning further instruction. Furthermore, we are interested in preservice teachers' behavioural patterns in 
dealing with their gaps in content knowledge during the use of the video vignettes.

\section{Selected Supportive Elements of the Learning Environment}

The learning arrangement simulates the three steps (the pre-actional-, actional- and post-actional phase) of the diagnostic process and our investigated preservice teachers carry out the steps as intended. The guiding structure of the learning environment succeeds in giving the preservice teachers the framework to stay on track and work intensively on the tasks. Digressions are rare during the peer group phase and preservice teachers are cognitively activated during the TSs with the video vignettes since all students are actively contributing to group discussions and on-topic in all videotapes.

Several elements integrated into the learning environment help preservice teachers structure their knowledge gain on the diagnostic process. They carry out schema-guided diagnosis of students' conceptions (DP6 is evident). For instance, the explicit separation of students' utterances and students' conceptions into two columns on the preservice teachers' worksheets causes them to focus on providing evidence for their interpretation of students' conceptions. Furthermore, the PostAP always starts with determining the most relevant students' conceptions which should be addressed in the next lesson, and therefore preservice teachers are engaged to focus on students' learning processes (DP2 is evident).

\section{Preservice Teachers' Gaps in Content Knowledge during Peer Discussions}

Preservice teachers' subject-specific issues first appear when they deal with the FCI item, which the high school students discuss in the training video vignette. Most of the preservice teachers in our sample ultimately tick the right answer for the FCI item, but their verbal and non-verbal behaviour indicates that they struggle with the requested explanations on a conceptual level. Explanations are either not given and missing (in TS-V1: S1, S2, S4), or there are preservice teachers who only differentiate their answer from an/some incorrect answer(s) and/or quote students' conceptions they know (in TS-V1 S3, in TS-V3 S5). Another strategy to explain the answer is, firstly, to write a fragmented answer (e.g., in TS-V2 S5: "upwards only the velocity") which can be interpreted in many ways. Secondly, the explanation only rephrases the original answer of the item (in TS-V2 S2, S4). None of these explanations are satisfying nor do they hint at content mastery on a deep conceptual level. Additionally, preservice teachers in our sample show their own misconceptions when correcting the wrong answer of the FCI item (e.g., in TSV2 S1, S2, S3, S6). Thus, their misconceptions seem to influence their thinking, and consequently some fail to justify their answers on a solid content level (in TS-V2 S1, S3, S6, in TS-V3 S1, S6).

Preservice teachers' gaps in content knowledge become evident during the peer discussions on basic concepts and their applications (e.g., Newton's $2^{\text {nd }}$ and $3^{\text {rd }}$ law). The preservice teachers intensively work on clarifying content issues, taking examples of application into account. Moreover, they try to extend their content knowledge and show their learning efforts since questions on content issues repeatedly arise (in TS-V1 S1, in TS-V2 and TS-V3 S5, S6). Hence, preservice teachers desire to fill their knowledge gaps in the peer discussion. The urge for exchange with their peers is so high that they even ignore the instructions in TS-V3 to individually carry out steps 1-3 (the full PreAP and AP) without any exchange with their peers. Instead, the preservice teachers communicate with their peers quietly and/or nonverbally by pointing at the worksheets of their neighbors (S6) and whispering to each other $(S 1, S 2, S 6, S 7)$ to compare their answers. They are clearly aware they are breaking the rules, but they intend to resolve their insecurity when exchanging thoughts with their peers. Thus, the question arises of how these insecurities on the content level influence the preservice teachers' learning behaviour during the training with the video vignettes.

The preservice teachers show their insecurity concerning their mastery of content knowledge already in the PreAP. They sometimes erase their first answers during the peer discussion and change or adapt them (e.g., in TS-V3: S1, S3, S5) or ultimately tick or change their answers after they gain certainty in the peer discussion (in TS-V1: S1, S2, S3, S4). Preservice teachers enter the diagnostic process with misconceptions which also manifest in their utterances during the peer discussions and which further influence their learning behaviour in different ways:

a) Misconceptions in preservice teachers' utterances are detected by at least one peer and addressed as an existing inadequate conception (e.g., in TS-V1 S4 detected a misconception of S1) - here we did not find any situation where a peer obviously detects a misconception of (an)other peer(s) and does not address it, since the detection of an inadequate conception relies on an issue being addressed;

b) Misconceptions in preservice teachers' utterances stay undetected within the peer group, but the peer group faces a general problem concerning the content knowledge shown in the peer discussion. This leads to not solving the task adequately (e.g., in TS-V2: equilibrium of forces and Newtons $3^{\text {rd }}$ law is mixed up by the peer group and the preservice teachers cannot clarify their content issue, which further results in the frustration of S1, S2, S6, S7); 
Table 4. Excerpt (translated from German) - analysed episode where a preservice teacher shows students' conceptions The excerpt shows a scene during the peer discussion of lesson planning.

\begin{tabular}{|c|c|c|c|}
\hline Step 0 (transcript) & Step 1 (micro-sequencing) & Step 2 (interpretation and reconstruction) & Step3 (extraction of thick meaning) \\
\hline $\begin{array}{l}\text { S2: } \\
\text { "Maybe, as teacher you } \\
\text { can take a toy car from } \\
\text { home and then you } \\
\text { precisely observe and } \\
\text { explain, that at the } \\
\text { beginning, when you } \\
\text { push the car, you almost } \\
\text { exert no force on the car } \\
\text { and only momentum is } \\
\text { transferred." } \\
\text { Nobody answers. }\end{array}$ & $\begin{array}{l}\text { S2 tries to describe a } \\
\text { possible lesson planning } \\
\text { scenario. She talks about a } \\
\text { toy car that the teacher } \\
\text { pushes and students } \\
\text { observe closely, and how, } \\
\text { as a teacher, this must be } \\
\text { explained in depth so that } \\
\text { the students understand } \\
\text { that there is "almost no } \\
\text { force" and only } \\
\text { momentum is passed on. }\end{array}$ & $\begin{array}{l}\text { S2 suggest for the lesson planning to explain } \\
\text { main concepts with the help of a toy car, } \\
\text { because she wants to contribute to the } \\
\text { discussion. She lacks in her description in } \\
\text { terms of content knowledge: She mentions } \\
\text { that when the car is pushed there is "almost } \\
\text { no force" acting and that there is only } \\
\text { momentum passed on. This is not true from a } \\
\text { physics standpoint, since the car first stands } \\
\text { still and then accelerates, so a force must have } \\
\text { acted on the car. Additionally, she uses the } \\
\text { wording "quasi no force" which indicates her } \\
\text { uncertainty about the concept of force. } \\
\text { Nobody objects to the statement of S2, and the } \\
\text { mistake on the content level is not discovered } \\
\text { within the peer group. }\end{array}$ & $\begin{array}{l}\text { Deficiencies in content knowledge } \\
\text { (and their understanding of } \\
\text { students' conceptions) influence } \\
\text { the preservice teachers' (S2) } \\
\text { thoughts on lesson planning and } \\
\text { thus their peer discussions. The } \\
\text { preservice teachers (S2) do not } \\
\text { recognize their mistakes in terms } \\
\text { of correctness according to physics } \\
\text { principles if nobody within their } \\
\text { peer group detects and points } \\
\text { them out. } \\
\text { Therefore, (some) inadequate } \\
\text { conceptions remain in the } \\
\text { preservice teachers' minds } \\
\text { throughout the peer discussion. }\end{array}$ \\
\hline
\end{tabular}

c) Misconceptions of preservice teachers stay undetected and frictionless discussion goes on (see e.g., Table 4).

In cases b) and c) preservice teachers do not undergo a conceptual change on the content level. This leads to the question: Which conditions help the peer group detect their peers' misconceptions during the group discussions?

One precondition for detecting misconceptions in the peer group is - not surprisingly - that at least one preservice teacher of the peer group must hold the competence needed to detect the misconception. This competence seems to be informed by profound content knowledge and the knowledge of this specific misconception (in TS-V1 S4). In TS-V1 in step 1, the students' conception that objects with greater mass fall significantly faster than objects with less mass is first shown by S1. S4 recognizes this and asks S1 why she thinks that. So, S4 initiates a discussion where also S2 and S3 show gaps in understanding. S4 explains the content in depth and shows profound content knowledge. A similar event was detected in TS-V2 in step 1 (solving the FCI item), where S1 and S5 obviously hold the misconception of impetus and again $S 4$ explains the physical facts. Additionally, S4 shows solid knowledge regarding students' conceptions in mechanics, since in TS-V2 when students' conceptions must be brainstormed, S4 named several students' conceptions and explained them to his peers. In brief, results derived from our sample indicate that preservice teachers must hold profound conceptual knowledge and knowledge about students' conceptions to be able to detect them in learners' utterances.

If profound content knowledge is absent in the peer group our sample shows case b) or c). When preservice teachers' inadequate conceptions stay undetected (case b), they get frustrated from repeatedly carrying out a cyclical process of discussion resulting in no solution (TS-V2 step 4). Here, preservice teachers do not seek support for example through online research with their smartphones or the lecturer. In case c, misconceptions are either not recognized as misconceptions or (implicitly seen as) not essential for further discussion.

\section{Preservice Teachers' Gaps in Content Knowledge when Working on Identifying Students' Conceptions and Lesson Planning}

In our sample, preservice teachers' gaps in content knowledge are also prominent in the phase of brainstorming students' conceptions relevant (based on key ideas in mechanics) for the intended learning processes and when interpreting them for planning further instruction. In the PreAP of TS-V1 preservice teachers received a list of possible students' conceptions derived from literature. Here, preservice teachers show problems in grasping the meaning of several students' conceptions since they cannot analyse them in enough depth to understand students' learning processes. For example S3 shows difficulties with the term "Schwung" (this is a German colloquial term for momentum, but it is often used when dissipation of impetus is meant) in the list of students' conceptions. S3 cannot connect the term with students' ideas of impetus and he does not identify the term "Schwung" as everyday language used to describe the technical term momentum. So, S3 does not connect "Schwung" with momentum and cannot derive possible reasons for students' learning problems.

Gaps in content knowledge influence preservice teachers' discussions on noticed students' utterances in the training video vignettes. When preservice teachers must discuss how they interpret students' utterances (see e.g., Table 3) regarding students' conceptions, they struggle to phrase their ideas on a content level and on a students' learning process level. In the presented episode in Table 3, the concept of momentum does not occur in the task of V3, but S6 mentions it and tries to apply the already acquired knowledge of previous TSs (TS-V1 and TS-V2) to the situation in TS-V3. However, 
the concept does not relate to the solution of the task or to a noticed student's utterance. Thus, S6 shows a behavioural pattern occurring when not sufficiently understanding the content.

Preservice teachers struggle to differentiate between misconceptions and basic ideas in mechanics. Without solid content knowledge, preservice teachers cannot identify physically correct and incorrect utterances ${ }^{10}$ (in TS-V2 S1, S2, S6, S7). This leads to obstacles when planning further instruction where students' conceptions (including misconceptions) and basic ideas must be considered. As a result, preservice teachers are not able to adapt learning goals to students' needs and deficits. Thus, preservice teachers plan further instruction in "working off" found students' mistakes without mentioning the main learning goal of the lesson (in TS-V3 S1, S2, S6, S7).

\section{Preservice Teachers' Strategies to Deal with Limited Content Knowledge}

Preservice teachers in our sample are aware of their limited content knowledge in physics. During group discussions, they bring up pervious experiences where they struggled to solve tasks on a conceptual basis (in TSV2: S1, S5). We reconstructed four reasons as to why they have not already - since they are at least in their $6^{\text {th }}$ semesters - addressed and fixed this issue:

1) There are preservice teachers who still think and/or hope to be exposed to appropriate learning opportunities in their future studies (S1, S2, S5). At this point it is, however, important to remember that all formal learning opportunities for mechanics are scheduled in semesters one to four and the students of our sample had already completed them.

2) It seems that preservice teachers are overtaxed and develop a feeling of a personal limited capability to acquire the required knowledge during their studies. They seem to lack ideas or strategies for how to fill the gap.

3) Preservice teachers do not have or do not take the time to address this issue during their studies, and they believe they will catch up on it when starting to teach. (In fact, our preservice teachers obviously do not practice solving physics problems on a conceptual level neither at secondary level in school nor at university.)

4) Another reason for ignoring the gaps in content knowledge is preservice teachers' experience with other peers having similar issues. Therefore, they may feel little reason to address their issue, since it is a commonly accepted issue in their peer group. Nevertheless, they are afraid of showing their (gaps in) content knowledge.

Preservice teachers in our sample show several strategies to cover up and cope with their gaps in content knowledge during the TSs. One strategy, especially used in the peer discussion phases, is to minimize active participation and stay as more passive listeners (e.g. in TS-V1, when S4 explains the difference of force and velocity: S1, S2, S3). Preservice teachers are obviously not used to learning environments which form an open and constructive culture of making errors. Thus, they seem to be afraid to show their problems concerning physics content. For example, they try to cover up their gaps in knowledge by repeating the exact wording of the task in their explanations, since they believe that everything that appears in the task must be correct (S2 in TS-V1 and TS-V2). Or, in the peer discussion, they drop incomplete and fragmented phrases which leave plenty of room for interpretation $(\mathrm{S} 1, \mathrm{~S} 2, \mathrm{~S} 3)$.

Aside from these strategies of communication among peers, the preservice teachers in our sample avoid showing their gaps in content knowledge to the lecturer. When they dare to ask the lecturer, they do not ask on a content level, they ask instead on a didactics level and try to extract content information on the subject level (in TS-V1 S1). Additionally, they start to discuss with particularly low voice (e.g., S1, S2, S6).

\section{DISCUSSION \& CONCLUSION}

Our study on preservice teachers' learning behaviour during trainings with video vignettes shows that gaps in content knowledge greatly influence their learning processes concerning the diagnosis of students' conceptions. This is in accordance with findings of Beretz et al. (2017), who showed that preservice teachers spend a considerable amount of time on content-specific clarification. In our study, we dug deeper by means of thick description (Geertz, 1973) and identified activities within the diagnostic process (e.g., solving tasks, brainstorming relevant students' conceptions, interpreting students' conceptions, planning instruction) physics preservice teachers struggle with, due to fragmented or insufficient content knowledge. Our findings underpin the assumption that content knowledge influences the diagnostic process (e.g., Beretz et al., 2017; Hoth et al., 2016; Ostermann, 2018; Star \& Strickland, 2008), which seems to be especially true for a diagnostic process focusing on students' conceptions. Preservice teachers in our sample show different patterns in hiding their misconceptions and insecurities in content knowledge. Additionally, they show gaps in knowledge and do not see the need to fill those gaps.

10 We are aware that one should not think in a black or white way in the learning process concerning correct or incorrect students' conceptions (Alonzo \& von Aufschnaiter, 2018) - nevertheless preservice teachers must be able to differentiate between correct and incorrect in order to set final goals for the learning process. 
Furthermore, in our sample, the preservice teachers' gaps in content knowledge lead to difficulties in connecting students' conceptions with students' learning processes. Difficulties in identifying and interpreting students' utterances regarding underlying students' conceptions are detected. They know several students' conceptions, but they struggle to interpret them in the context of students' learning. This underpins hints of Hoppe et al. (2020), who detected preservice teachers' difficulties in interpreting students' comments in the context of learning processes. Additionally, Hoppe et al. (2020) found significant and moderate correlations between content knowledge and diagnostic skills in biology education. Our results indicate that this is also true for physics teacher education. In our sample, gaps in content knowledge challenge preservice teachers when planning further instruction. Preservice teachers in our sample are familiar with (some) students' conceptions, and they use the strategy of simply "working through" these students' conceptions. This corresponds with the results of Stahnke et al. (2016), who found that many teachers' method of choice is providing correct answers for their students without having a deeper understanding of the students' conceptions.

The following question arises: Which content knowledge and pedagogical content knowledge is needed to carry out an ideal diagnostic process? Our data indicates that common misconceptions of preservice teachers are triggered using the FCI itembased video vignettes. This is not surprising, as FCI items cover the most common misconceptions of Newtonian mechanics. Our results show that knowledge of students' conceptions seems to help preservice teachers carry out the (simulated) diagnostic process.

Furthermore, the preservice teachers in our sample use the training sessions working with the video vignettes as learning opportunities to gain content knowledge (see Table 2). Most of the students in our sample show a higher score in the selected FCI items in the post-test compared to the pre-test. Nevertheless, most of the preservice teachers still do not solve all the FCI items correctly. This indicates that the majority in our sample still show insufficient content knowledge on a deep conceptual level. Obviously, more intervention is needed to promote conceptual change of their deeply rooted misconceptions in the field of content knowledge.

Despite the deep insights we gain from our preservice teachers' learning behaviour during the use of video vignettes to foster their diagnostic competence in diagnosing students' conceptions, our data must be interpreted carefully due to several limitations. As our study is a qualitative study with a small sample, no generalizations should be made. Data was collected in one physics didactics course at one institution. Therefore, preservice teachers studying at other institutions may show variations of the patterns of preservice teachers' learning behaviour found here.
Additionally, one weakness of the used method of thick description is the concept of a dissociated researcher (Geertz, 1973), which cannot be fully fulfilled, as a researcher always sets the basis for interpretation from his/her own cultural background (Geertz, 1973). This means that researchers are always influenced by their individual backgrounds, which cannot be disconnected from the analysis. Nevertheless, this goes along with the advantage that the researcher is able to focus on aspects others would not detect. As the researchers' background (part of the data was analysed together with a coresearcher) is physics education, it was possible to pursue the main aim, namely the reconstruction of preservice teachers' intentions of actions during the use of training video vignettes to better understand the obstacles preservice teachers face and cope with in the teaching and learning setting.

\section{Redesign of the Learning Environment}

Following the iterative cycles of design, implementation and redesign according to design-based research, we develop the second version of the learning environment based on the findings of cycle one. The most important adaptions are as follows: First, we set stable peer groups based on the pre-test on content knowledge (6 FCI items). Each group should include at least one preservice teacher with profound content knowledge (all 6 FCI items correct) to increase the chance of solving (individual) content issues in the peer group. Second, the content clarification process and solving process of the FCI item used in TS-V1 is changed to an out of class team activity. As scaffolds, we recommend literature and a digital exchange forum. This change individualizes the step of content clarification and preservice teachers then have the chance to take as much time as necessary for individual research. Third, we open the opportunity for a safe environment for discussion where only the peers and the lecturer take part. Therefore, preservice teachers must engage more deeply with the topic, because their task is to justify their answers and explain why the other options of the FCI item are incorrect (Beretz et al., 2017). With this element, we try to ensure a certain level of content knowledge we assume is necessary for diagnosis. Furthermore, we want to create a constructive learning environment where they do not feel the need to hide their gaps in knowledge.

Additionally, we add micro-teachings with roleplay elements, where preservice teachers take the role of a high school student who holds certain students' conceptions. We try to initiate a change of perspective. In this way, we want to support preservice teachers in deriving possible students' utterances from given students' conceptions so that the preservice teachers also practice the process of thinking of possible students' utterances based on given students' conceptions (and the other way around). Thereby, the preservice teachers 
should deepen their thinking from the point of view of the learning process of a student.

Furthermore, in the second version of the learning environment, we still follow the introduced schema of the diagnostic process and the instruction. The preactional, actional and post-actional phases are carried out by the preservice teachers during the training sessions. However, we use two training video vignettes instead of three. So, the preservice teachers have more time to discuss, apply and anticipate their knowledge. The scaffolding approach is still utilized in the second version of the learning environment. Furthermore, we still want to simulate a diagnostic situation where preservice teachers carry out the steps of the diagnostic process on their own. As diagnostic situations are stressful, they can impair cognitive capacities negatively influencing the diagnostic process (Becker et al., 2020), so preservice teachers need to train for these stressful situations (Embse et al., 2019) so as to free up cognitive resources in the actional phase, to optimize the diagnostic process. Additionally, we slightly shift our instruction onto fruitful elements of students' conceptions (Alonzo \& von Aufschnaiter, 2018) to widen preservice teachers' planning consideration in terms of students' conceptions as a fruitful resource for learning.

\section{Conclusion}

Preservice teachers of our sample face several obstacles when training to diagnose students' conceptions with video vignettes. Content knowledge (in our case content knowledge in mechanics) or gaps in content knowledge seem to influence preservice teachers' peer discussion to a high degree. Several strategies of preservice teachers to cover up these gaps in content knowledge lead to problems that are difficult to detect during the physics didactics course. Nevertheless, a deeper analysis of the videotapes of the preservice teachers dealing with classroom video vignettes allowed us to uncover some hidden obstacles. We assume that our results concerning preservice teachers' learning behaviour in training sessions on diagnosing students' conceptions are transferable to other areas in physics teacher education and even to other disciplines, since content knowledge is needed for several professional tasks of future teachers, and peer discussions are a common method used in (teacher education) courses.

Our study shows the value of looking at the training of the whole diagnostic process and identifying continuous patterns in preservice teachers' learning behaviour to improve the learning environment concerning diagnostic competence related to students' conceptions. Nevertheless, further analysis and more research must be carried out to more deeply investigate other obstacles preservice teachers face during the use of video vignettes. Thus, our study is just a first step, and more research is needed to understand the underlying patterns which influence (preservice) teachers' behaviour in acquiring diagnostic competence.

Author contributions: All authors have sufficiently contributed to the study, and agreed with the results and conclusions.

Funding: No funding source is reported for this study.

Declaration of interest: No conflict of interest is declared by authors.

\section{REFERENCES}

Alonzo, A. C., \& von Aufschnaiter, C. (2018). Moving Beyond Misconceptions: Learning Progressions as a Lens for Seeing Progress in Student Thinking. The Physics Teacher, 56(7), 470-473. https://doi.org/ $10.1119 / 1.5055332$

Barab, S., \& Squire, K. (2004). Design-Based Research: Putting a Stake in the Ground. Journal of the Learning Sciences, 13(1), 1-14. https://doi.org/10.1207/ s15327809j1s1301_1

Beck, E., Baer, M., Guldimann, T., Bischoff, S., Brühwiler, C., Müller, P., Niedermann, R., Rogalla, M., \& Vogt, F. (Eds.). (2008). Pädagogische Psychologie und Entwicklungspsychologie: Vol. 63. Adaptive Lehrkompetenz: Analyse und Struktur, Veränderbarkeit und Wirkung handlungssteuernden Lehrerwissens [Educational psychology and developmental psychology: Vol. 63. Adaptive teaching competence: Analysis and structure, changeability and effect of action-controlling teacher knowledge]. Waxmann.

Becker, S., Spinath, B., Ditzen, B., \& Dörfler, T. (2020). Der Einfluss von Stress auf Prozesse beim diagnostischen Urteilen - eine Eye Tracking-Studie mit mathematischen Textaufgaben. Unterrichtswissenschaft, 48, 531-550. https: / / doi.org /10.1007/s42010-020-00078-4

Beretz, A.-K., Lengnink, K., \& von Aufschnaiter, C. (2017). Diagnostische Kompetenz gezielt fördern Videoeinsatz im Lehramtsstudium Mathematik und Physik [Targeted promotion of diagnostic competence - use of video in mathematics and physics teacher training]. In C. Selter, S. Hußmann, C. Hößle, C. Knipping, K. Lengnink, \& J. Michaelis (Eds.), Diagnose und Förderung heterogener Lerngruppen: Theorien, Konzepte und Beispiele aus der MINT-Lehrerbildung [Diagnosis and promotion of heterogeneous learning groups: theories, concepts and examples from MINT teacher training] (pp. 149-168). Waxmann.

Berliner, D. C. (2001). Learning about and learning from expert teachers. International Journal of Educational Research, 35(5), 463-482. https://doi.org/10.1016/ S0883-0355(02)00004-6

Black, P., \& Wiliam, D. (1998). Assessment and Classroom Learning. Assessment in Education: Principles, Policy E Practice, 5(1), 7-74. https:/ / doi.org/10.1080/0969595980050102 
Black, P., \& Wiliam, D. (2003). 'In praise of educational research': formative assessment. British Educational Research Journal, 29(5), 623-637. https://doi.org/ $10.1080 / 0141192032000133721$

Blomberg, G., Renkl, A., Sherin, M. G., Borko, H., \& Seidel, T. (2013). Five research-based heuristics for using video in pre-service teacher education. Journal for Educational Research Online, 5(1), 90-114.

Blomberg, G., Sherin, M. G., Renkl, A., Glogger, I., \& Seidel, T. (2014). Understanding video as a tool for teacher education: investigating instructional strategies to promote reflection. Instructional Science, 42(3), 443-463. https://doi.org/10.1007/ s11251-013-9281-6

Blömeke, S., Gustafsson, J.-E., \& Shavelson, R. J. (2015). Beyond Dichotomies. Zeitschrift Für Psychologie, 223(1), 3-13. https:// doi.org/10.1027/21512604/a000194

Carter, K., Cushing, K., Sabers, D., Stein, P., \& Berliner, D. (1988). Expert-Novice Differences in Perceiving and Processing Visual Classroom Information. Journal of Teacher Education, 39(3), 25-31. https: / / doi.org/10.1177/002248718803900306

Denzin, N. K. (1989). Interactionism, Interpretive: Applied Social Research Methods Series (vol. 16). Sage.

Duit, R. (1994). An Schülervorstellungen anknüpfend Physik lehren und lernen [Teaching and learning physics based on student ideas]. Naturwissenschaft Im Unterricht Physik, 5(22), 4-6.

Duit, R. (1996). The constructivist view in science education-what it has to offer and what should not be expected from it. Investigaçôes Em Ensino De Ciências, 1(1), 40-75.

Duit, R., Gropengießer, H., Kattmann, U., Komorek, M., \& Parchmann, I. (2012). The Model of Educational Reconstruction - a framework for improving teaching and learning science. In D. Jorde \& J. Dillon (Eds.), Cultural perspectives in science education: Vol. 5. Science education research and practice in Europe: Retrospective and prospective. Sense Publ. https:/ / doi.org/10.13140/2.1.2848.6720

Duit, R., Treagust, D., \& Widodo, A. (2008). Teaching science for conceptual change: Theory and practice. In International handbook of research on conceptual change (pp. 629-646). Routledge.

Embse, N., Ryan, S. V., Gibbs, T., \& Mankin, A. (2019). Teacher stress interventions: A systematic review. Psychology in the Schools, 56(8), 1328-1343. https://doi.org/10.1002/pits.22279

Fischer, C., Veber, M., \& Rott, D. (2014). Adaptive Lehrkompetenz und pädagogische Haltung [Adaptive teaching skills and pedagogical attitude]. In E. Kiel, I. Esslinger-Hinz, \& K. Reusser (Eds.), Jahrbuch für Allgemeine Didaktik: Vol. 2014.
Thementeil: Allgemeine Didaktik für eine inklusive Schule (pp. 16-34). Schneider Verlag Hohengehren.

Freeman, M. (2014). The Hermeneutical Aesthetics of Thick Description. Qualitative Inquiry, 20(6), 827833. https:/ / doi.org/10.1177/1077800414530267

Geertz, C. (1973). The interpretation of cultures: Selected Essays by Clifford Geertz. Basic Books, Inc., Publishers. https://chairoflogicphiloscult.files. wordpress.com/2013/02/clifford-geertz-theinterpretation-of-cultures.pdf

Geertz, C. (2015). Dichte Beschreibung: Beiträge zum Verstehen kultureller Systeme [Dense description: Contributions to the understanding of cultural systems] (B. Luchesi \& R. Bindemann, Trans.) (13. Ed.). Suhrkamp-Taschenbuch Wissenschaft: Vol. 696. Suhrkamp.

Greenwood, J. (1993). Reflective practice: A critique of the work of Argyris and Schön. Journal of Advanced Nursing, 18(8), 1183-1187. https:/ / doi.org/10.1046 /j.1365-2648.1993.18081183.x

Grossman, P., Compton, C., Igra, D., Ronfeldt, M., Shahan, E., \& Williamson, Peter, W. (2009). Teaching Practice: A Cross-Professional Perspective. Teachers College Record, 111(9), 20552100 .

Haagen-Schützenhöfer, C., \& Hopf, M. (2020). Designbased research as a model for systematic curriculum development: The example of a curriculum for introductory optics. Physical Review Physics Education Research, 16(2), 020152. https:/ / doi.org/10.1103/PhysRevPhysEducRes.16.020152

Hattie, J. (2012). Visible learning for teachers: Maximizing impact on learning. Routledge. https://doi.org/ $10.4324 / 9780203181522$

Helmke, A. (2009). Unterrichtsqualität und Lehrerprofessionalität: Diagnose, Evaluation und Verbesserung des Unterrichts [Teaching quality and teacher professionalism: diagnosis, evaluation and improvement of teaching] (1. Ed.). Klett-Kallmeyer.

Herppich, S., Praetorius, A.-K., Hetmanek, A., Glogger, I., Ufer, S., Leutner, D., Behrmann, L., Böhmer, I., Böhmer, M., Förster, N., Kaiser, J., Karing, C., Karst, K., Klug, J., Ohle, A., \& Südkamp, A. (2017). Ein Arbeitsmodell für die empirische Erforschung der diagnostischen Kompetenz von Lehrkräften [A working model for empirical research into the diagnostic competence of teachers]. In A. Südkamp \& A.-K. Praetorius (Eds.), Diagnostische Kompetenz von Lehrkräften: Theoretische und methodische Weiterentwicklungen [Diagnostic competence of teachers: Theoretical and methodological developments]. Waxmann Verlag $\mathrm{GmbH}$.

Hestenes, D., Wells, M., \& Swackhamer, G. (1992). Force concept inventory. The Physics Teacher, 30(3), 141158. https:/ / doi.org/10.1119/1.2343497 
Hoppe, T., Renkl, A., Seidel, T., Rettig, S., \& Rieß, W. (2020). Exploring How Teachers Diagnose Student Conceptions about the Cycle of Matter. Sustainability, 12(10), 4184. https://doi.org/ $10.3390 /$ su12104184

Hoth, J., Döhrmann, M., Kaiser, G., Busse, A., König, J., \& Blömeke, S. (2016). Diagnostic competence of primary school mathematics teachers during classroom situations. ZDM, 48(1-2), 41-53. https: / / doi.org/10.1007/s11858-016-0759-y

Ingenkamp, K.-H., \& Lissmann, U. (2008). Lehrbuch der Pädagogischen Diagnostik [Educational diagnostics textbook]. Beltz Verlag.

Klug, J., Bruder, S., \& Schmitz, B. (2016). Which variables predict teachers diagnostic competence when diagnosing students' learning behavior at different stages of a teacher's career? Teachers and Teaching, 22(4), 461-484. https://doi.org/10.1080/13540602. 2015.1082729

Klug, J., Bruder, S., Kelava, A., Spiel, C., \& Schmitz, B. (2013). Diagnostic competence of teachers: A process model that accounts for diagnosing learning behavior tested by means of a case scenario. Teaching and Teacher Education, 30, 38-46. https://doi.org/10.1016/j.tate.2012.10.004

Klug, J., Gerich, M., \& Schmitz, B. (2016). Can teachers' diagnostic competence be fostered through training and the use of a diary? Journal for Educational Research Online, 8, 184-206.

Leeds-Hurwitz, W. (2015). Thick Description. In K. Tracy, C. Ilie, \& T. Sandal (Eds.), The international encyclopedia of language and social interaction. The international encyclopedia of language and social interaction (pp. 1-5). Wiley-Blackwell. https://doi. org/10.1002/9781118611463.wbielsi072

Leuders, T., Dörfler, T., Leuders, J., \& Philipp, K. (2018). Diagnostic Competence of Mathematics Teachers: Unpacking a Complex Construct. In T. Leuders, K. Philipp, \& J. Leuders (Eds.), Mathematics Teacher Education: Vol. 11. Diagnostic competence of mathematics teachers: Unpacking a complex construct in teacher education and teacher practice (pp. 3-32). Springer. https://doi.org/10.1007/978-3-31966327-2

Levin, D. M., Hammer, D., \& Coffey, J. E. (2009). Novice Teachers' Attention to Student Thinking. Journal of Teacher Education, 60(2), 142-154. https://doi.org/ $10.1177 / 0022487108330245$

Livingston, C., \& Borko, H. (1989). Expert-Novice Differences in Teaching: A Cognitive Analysis and Implications for Teacher Education. Journal of Teacher Education, 40(4), 36-42. https://doi.org/ $10.1177 / 002248718904000407$

McManus, S. (2008). Attributes of effective formative assessment. Council of Chief State School Officers.
Meister, S., Nitz, S., Schwanewedel, J., \& Upmeier zu Belzen, A. (2020). Diagnostische Fähigkeiten Lehramtsstudierender - Förderung mit Videovignetten und Anwendung im Lehr-LernLabor [Diagnostic skills of student teachers promotion with video vignettes and application in the teaching-learning laboratory]. In B. Priemer \& J. Roth (Eds.), Lehr-Lern-Labore: Konzepte und deren Wirksamkeit in der MINT-Lehrpersonenbildung [Teaching-learning laboratories: Concepts and their effectiveness in MINT teacher training] (1st ed., Vol. 16, pp. 223-247). Springer Berlin Heidelberg. https: / / doi.org/10.1007/978-3-662-58913-7_15

Ostermann, A. (2018). Factors Influencing the accuracy of diagnostic judgements. In T. Leuders, K. Philipp, \& J. Leuders (Eds.), Mathematics Teacher Education: Vol. 11. Diagnostic competence of mathematics teachers: Unpacking a complex construct in teacher education and teacher practice (pp. 95-108). Springer.

Ponterotto, J. G. (2006). Brief note on the origins, evolution, and meaning of the qualitative research concept thick description. The Qualitative Report, 11(3), 538-549.

Rath, V. (2017). Diagnostische Kompetenz von angehenden Physiklehrkräften. Modellierung, Testinstrumentenentwicklung und Erhebung der Performanz bei der Diagnose von Schülervorstellungen in der Mechanik. Studien zum Physik- und Chemielernen (Vol. 220). Logos Verl.

Sabers, D. S., Cushing, K. S., \& Berliner, D. C. (1991). Differences Among Teachers in a Task Characterized by Simultaneity, Multidimensional, and Immediacy. American Educational Research Journal, 28(1), 63-88. https://doi.org/10.3102/ 00028312028001063

Santagata, R., \& Yeh, C. (2016). The role of perception, interpretation, and decision making in the development of beginning teachers' competence. ZDM, 48(1-2), 153-165. https://doi.org/10.1007/ s11858-015-0737-9

Schön, D. A. (1987). Educating the reflective practitioner: Toward a new design for teaching and learning in the professions (1. ed.). The Jossey-Bass higher education series. Jossey-Bass.

Schubert, T., Friedmann, F., \& Regenbrecht, H. (2001). The Experience of Presence: Factor Analytic Insights. Presence: Teleoperators and Virtual Environments, 10(3), 266-281. https://doi.org/ $10.1162 / 105474601300343603$

Schwandt, T. A. (2007). The Sage dictionary of qualitative inquiry (3. ed.). Sage Publ. https://doi.org/ $10.4135 / 9781412986281$

Seidel, T., Blomberg, G., \& Renkl, A. (2013). Instructional strategies for using video in teacher education. 
Teaching and Teacher Education, 34, 56-65. https://doi.org/10.1016/j.tate.2013.03.004

Sherin, M. G., \& van Es, E. A. (2009). Effects of Video Club Participation on Teachers' Professional Vision. Journal of Teacher Education, 60(1), 20-37. https://doi.org/10.1177/0022487108328155

Sherin, M. G., Jacobs, V. R., \& Philipp, R. A. (2011). Mathematics Teacher Noticing. Routledge. https:/ / doi.org/10.4324/9780203832714

Stahnke, R., Schueler, S., \& Roesken-Winter, B. (2016). Teachers' perception, interpretation, and decisionmaking: a systematic review of empirical mathematics education research. ZDM, 48(1-2), 127. https:/ / doi.org/10.1007/s11858-016-0775-y

Star, J. R., \& Strickland, S. K. (2008). Learning to observe: using video to improve preservice mathematics teachers' ability to notice. Journal of Mathematics Teacher Education, 11(2), 107-125. https:/ / doi.org/10.1007/s10857-007-9063-7

Steffentorweihen, B., \& Theyßen, H. (2018). Diagnostische Fähigkeiten fördern im Lehr-LernLabor Physik [Diagnostic skills promote physics in the teaching-learning laboratory]. PhyDid B Didaktik Der Physik - Beiträge Zur DPGFrühjahrstagung (pp. 179-184).

Suchań, B., \& Breit, S. (Eds.). (2016). PISA 2015. Grundkompetenzen am ende der pflichtschulzeit im internationalen vergleich [PISA 2015. Basic skills at the end of compulsory schooling in an international comparison]. Leykam.

Tekkumru-Kisa, M., Stein, M. K., \& Coker, R. (2018). Teachers' learning to facilitate high-level student thinking: Impact of a video-based professional development. Journal of Research in Science Teaching, 55(4), 479-502. https:// doi.org/10.1002/ tea.21427

Tolsdorf, Y., \& Markic, S. (2017). Development of an instrument and evaluation pattern for the analysis of chemistry student teachers' diagnostic competence. International Journal of Physics $\mathcal{E}$ Chemistry Education, 9(3), 1-10.

Tolsdorf, Y., \& Markic, S. (2018). Development and Changes in Student Teachers' Knowledge Concerning Diagnostic in Chemistry Teaching - A Longitudinal Case Study. Eurasia Journal of Mathematics, Science and Technology Education, 14(12), em1613. https://doi.org/10.29333/ejmste/ 94232

van Es, E. A., \& Sherin, M. G. (2002). Learning to Notice: Scaffolding New Teachers' Interpretations of
Classroom Interactions. Journal of Technology and Teacher Education, 10(4), 571-596.

van Es, E. A., \& Sherin, M. G. (2008). Mathematics teachers" "learning to notice" in the context of a video club. Teaching and Teacher Education, 24(2), 244-276. https://doi.org/10.1016/j.tate.2006.11.005

van Merrienboer, J. J. G., Kirschner, P. A., \& Kester, L. (2003). Taking the Load Off a Learner's Mind: Instructional Design for Complex Learning. Educational Psychologist, 38(1), 5-13. https://doi.org/10.1207/S15326985EP3801_2

van Ophuysen, S. (2010). Professionelle pädagogischdiagnostische Kompetenz - eine theoretische und empirische Annäherung [Professional educationaldiagnostic competence - a theoretical and empirical approach]. In H.-G. Rolff (Ed.), Veröffentlichungen des Instituts für Schulentwicklungsforschung. Jahrbuch der Schulentwicklung: Daten, Beispiele und Perspektiven (1st ed., pp. 203-234). Beltz.

Vogt, F., \& Rogalla, M. (2009). Developing Adaptive Teaching Competency through coaching. Teaching and Teacher Education, 25(8), 1051-1060. https:// doi.org/10.1016/j.tate.2009.04.002

von Aufschnaiter, C., \& Alonzo, A. C. (2018). Foundations of formative assessment: Introducing a learning progression to guide preservice physics teachers' video-based interpretation of student thinking. Applied Measurement in Education, 31(2), 113-127. https:// doi.org/10.1080/08957347.2017.1408629

von Aufschnaiter, C., Cappell, J., Dübbelde, G., Ennemoser, M., Mayer, J., Stiensmeier-Pelster, J., Sträßer, R., \& Wolgast, A. (2015). Diagnostische Kompetenz: Theoretische Überlegungen zu einem zentralen Konstrukt der Lehrerbildung [Diagnostic competence: Theoretical considerations on a central construct of teacher training]. Zeitschrift Für Pädagogik, 61(5), 738-758.

Weinert, F. E. (2001). Concept of Competence: A Conceptual Clarification. In D. S. Rychen \& L. H. Salganik (Eds.), Defining and Selecting Key Competencies (pp. 45-66). Hogrefe.

Weinert, F. E., Schrader, F.-W., \& Helmke, A. (1989). Quality of instruction and achievement outcomes. International Journal of Educational Research, 13(8), 895-914. https://doi.org/10.1016/0883-0355(89) $90072-4$

\section{http://www.ejmste.com}

